\title{
Non-transferrin bound iron and neutropenia after cytotoxic chemotherapy
}

\author{
P Harrison, S S Marwah, R T Hughes, D Bareford
}

\begin{abstract}
Aims-To investigate and characterise the appearance of non-transferrin bound iron (NTBI) in the serum of patients after cytotoxic chemotherapy and to compare this with the onset and duration of neutropenia.
\end{abstract}

Method-Non-transferrin bound iron was measured by a bleomycin assay in patients undergoing intensive chemotherapy for treatment of acute leukaemia or lymphoma.

Results-NTBI was detected after 26 of 27 courses of chemotherapy and lasted for a mean of 14.5 days. The presence of NTBI correlated with the serum iron binding saturation, but not with serum ferritin. Neutropenia occurred after all courses of chemotherapy and lasted for a mean of 20.0 days. NTBI and neutropenia occurred concurrently after 23 courses of chemotherapy, and had a mean joint duration of 9.5 days.

Conclusions-NTBI is consistently present in the serum of patients after cytotoxic chemotherapy, often at the same time as the patient is neutropenic. This may be an additional risk factor for the development of infective episodes after chemotherapy.

(F Clin Pathol 1994;47:350-352)

In patients with chronic iron overload serum transferrin becomes fully saturated and an abnormal iron fraction can appear in the serum. This effect has been reported in several conditions including idiopathic haemachromatosis, ${ }^{1}$ and in patients with $\beta$ thalassaemia trait and chronic active hepatitis. ${ }^{2}$ Patients with acute leukaemia have been reported to have high serum iron concentrations and high levels of transferrin saturation. ${ }^{34}$ Intensive cytotoxic chemotherapy would be expected to release intracellular iron from cells undergoing cytolysis. This could result in total saturation of serum iron binding capacity followed by the appearance of a circulating non-transferrin bound iron (NTBI) fraction.

The presence of iron is essential for the growth of almost all bacteria, and normally serum iron is relatively unavailable to bacteria as it is bound to transferrin or ferritin. The presence of NTBI in the serum of patients after cytotoxic chemotherapy would therefore be an additional risk factor (to that of neutropenia) for the development of infective episodes.

To investigate and characterise the appearance of NTBI after chemotherapy, NTBI together with serum iron, serum total iron binding capacity, and serum ferritin were measured in patients undergoing cytotoxic chemotherapy for haematological malignancies.

\section{Methods}

Patients with acute leukaemia or lymphoma undergoing combination cytotoxic chemotherapy for either remission induction or consolidation were studied. The study was carried out at Dudley Road Hospital, Birmingham. All patients received conventional doses of chemotherapy. The patients were venesected at least three times a week for full blood counts, and serum samples were taken routinely for iron studies at the same time. A serum sample was taken from all patients before the start of chemotherapy. Full blood counts were performed on a Technicon $\mathrm{H}^{\star} 1$ analyser (Technicon Corporation, New York, USA). For this study neutropenia was defined as an absolute neutrophil count of less than $0.5 \times 10^{9} / 1$. The follow up period ended when either a further course of chemotherapy was given, two consecutive samples were negative for NTBI after the end of the neutropenic period, or a total of 55 days had elapsed, whichever was the shorter. A total of 10 patients were studied during 27 courses of combination chemotherapy. Table 1 shows details of patient age, sex, and diagnosis.

The bleomycin assay used to measure NTBI has been described previously. ${ }^{5}$ Briefly, $0.4 \mathrm{ml}$ of $1 \mathrm{mg} / \mathrm{ml} \mathrm{DNA} \mathrm{(Sigma} \mathrm{Chemical}$ Company, Poole, Dorset), $50 \mu 1$ of $0.6 \mathrm{mM}$ bleomycin (Lundbeck, Luton), $0.1 \mathrm{ml}$ of 50 $\mathrm{mM}$ magnesium chloride (BDH Chemicals Ltd, Poole, Dorset), $0.1 \mathrm{ml}$ TRIS buffer, $\mathrm{pH}$ $7.4(\mathrm{BDH}), \quad 50 \mu \mathrm{l}$ of $7.5 \mathrm{mM}$ ascorbate $(\mathrm{BDH})$, and $20 \mu \mathrm{l}$ of sample or control were incubated in clean plastic test tubes for 30 minutes at $37^{\circ} \mathrm{C}$. Then $0.1 \mathrm{ml}$ of $0.1 \mathrm{M}$ EDTA (BDH), $0.5 \mathrm{ml}$ of $1 \% \mathrm{w} / \mathrm{v}$ thiobarbituric acid (TBA) in $50 \mathrm{mM}$ sodium hydroxide (Sigma), and $0.5 \mathrm{ml}$ of hydrochloric acid $25 \%$ $\mathrm{w} / \mathrm{v}$ in distilled water (BDH) were added and the mixture heated for five minutes at $100^{\circ} \mathrm{C}$ to develop TBA reactivity. After cooling the absorbence was measured at $532 \mathrm{~nm}$ with a 
Table 1 Patient details

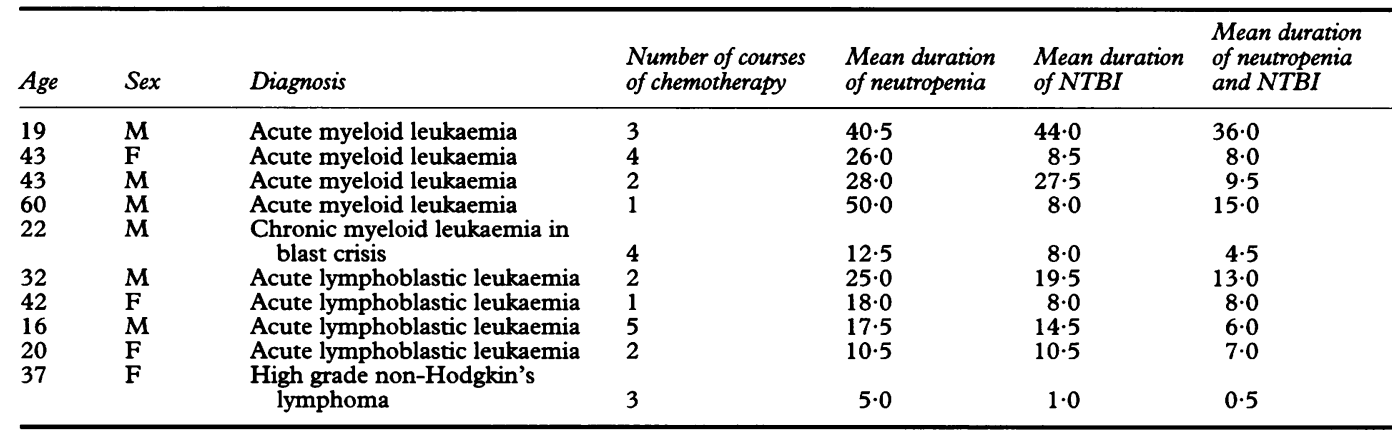

Table 2 NTBI and serum iron binding saturation

\begin{tabular}{lcc}
\hline $\begin{array}{l}\text { \% Serum total iron } \\
\text { binding saturation }\end{array}$ & $\begin{array}{l}\text { NTBI Positive } \\
\text { (\% of all samples) }\end{array}$ & $\begin{array}{l}\text { NTBI Negative } \\
\text { (\% of all samples) }\end{array}$ \\
\hline$<50$ & 1.5 & $19 \cdot 5$ \\
$51-80$ & 1.0 & 17.0 \\
$81-90$ & 10.5 & $5 \cdot 0$ \\
$91-100$ & 32.5 & 3.5 \\
\hline
\end{tabular}

PU 8610 kinetics spectrophotometer (Pye Unicam) and compared with the appropriate standards and blanks.

Serum iron and iron binding capacity were analysed colorimetrically on a Technicon autoanalyser 11 (Technicon Instruments Corporation, New York, USA), and serum ferritin by an immunoradiometric assay (Becton Dickinson, Oxford)

The bleomycin assay used to measure serum NTBI does not measure iron bound to transferrin or ferritin, only low molecular weight iron ions capable of stimulating free radical reactions. ${ }^{56}$

The association between high serum iron binding saturation and the detection of NTBI was tested by the Wilcoxon rank sum test. The correlation between serum ferritin concentrations and NTBI was tested by calculating the correlation coefficient and then applying a $t$ test.

\section{Results}

NTBI was not detected in any of the patients before the start of chemotherapy, but was found after 26 of the 27 courses of chemotherapy studied (mean follow up period 33.5 days). NTBI was detected at a mean of 5.5 (range 2-17) days after the start of chemotherapy, and was detectable for a mean of 14.5 days. Concentrations of NTBI up to $28 \mu \mathrm{M} / 1$ were found; however, most positive samples had values between $0 \cdot 1$ and $10.0 \mu \mathrm{M} / 1$, and the mean was $4.3 \mu \mathrm{M} / 1$. NTBI was only detected in samples with serum total

Table 3 NTBI and serum ferritin

\begin{tabular}{ll}
\hline $\begin{array}{l}\text { Serum ferritin } \\
(\mu g / l)\end{array}$ & $\begin{array}{l}\text { \% of NTBI } \\
\text { Positive samples }\end{array}$ \\
\hline$<1000$ & 24.5 \\
$1001-2000$ & 23.0 \\
$2001-3000$ & $19 \cdot 5$ \\
$3001-4000$ & 33.0 \\
\hline
\end{tabular}

iron binding saturation at or approaching $100 \%$ (table 2). The mean serum iron binding saturation in samples found to contain NTBI was $93.9 \%$ compared with $56.3 \%$ for those in which NTBI was absent $(p<0.001)$. Conversely, although serum ferritin concentrations as high as $4000 \mu \mathrm{g} / 1$ were recorded, there was no correlation between the serum ferritin and the presence of NTBI $(r=0 \cdot 1$, p > 0.2), (table 3 ). All 27 courses of cytotoxic chemotherapy resulted in a period of neutropenia. The onset of neutropenia occurred a mean of six (range 0-11) days after the start of chemotherapy and had a mean duration of 20 days. NTBI and neutropenia occurred concurrently at least once in all patients studied. Concurrent neutropenia and NTBI occurred after 23 of the 27 courses of chemotherapy with a mean duration of 9.5 (range one to 38) days.

\section{Discussion}

This study shows that NTBI is consistently present in the serum of patients after cytotoxic chemotherapy; often at the same time as the patient is neutropenic. The appearance of NTBI corresponds to the saturation of serum total iron binding capacity, and shows no correlation to the level of serum ferritin.

The study confirms a previously reported finding that NTBI is present in the serum of patients after intensive cytotoxic chemotherapy for the treatment of acute leukaemia. ${ }^{7}$ Unlike this previous report, however, we did not detect NTBI before the start of chemotherapy.

Caroline et $a l^{3}$ showed not only that patients with acute leukaemia had high and often fully saturated iron binding capacity but that their serum enhanced the growth of candida in vitro compared with normal serum. A further study reported differences in survival in acute lymphoblastic leukaemia between patients with a low versus high transferrin saturation. ${ }^{8}$ In this study patients with a transferrin saturation of less than $36 \%$ were found to have a lower death rate than those with a saturation greater than this. It was not, however, possible to say from this study whether infection accounted for some of the differences in survival.

There are several reasons why an NTBI fraction might lead to an increased incidence of infections. Firstly, iron is essential for the 
growth of almost all bacteria, and, under normal circumstances, serum iron is relatively unavailable to bacteria as it is bound to transferrin or ferritin. Supportive evidence for this comes from the many studies showing that the in vitro bacteriostatic effect of serum is lost when transferrin is saturated. ${ }^{9}$ The importance of iron for bacterial growth is further highlighted by some pathogenic species in which plasmids associated with increased virulence code for sideropores that facilitate iron uptake. ${ }^{10}$

Evidence has been summarised which suggests that the host's ability to fight infection may be impaired in several ways by high concentrations of iron. ${ }^{11}{ }^{12}$ In particular, in vitro lymphocyte proliferation may be reduced when transferrin saturation nears $100 \%{ }^{13}$; and phagocytosis of bacteria by neutrophils is reduced after exposure to iron salts. ${ }^{14}$

Another mechanism by which NTBI may be detrimental to the leukaemic patient is by free radical mediated tissue damage. It has been suggested that NTBI may mediate tissue damage by the formation of highly reactive hydroxyl radicals from superoxide and hydrogen peroxide. Also, it is known that certain chemotherapeutic agents, such as doxorubicin, promote the generation of both superoxide and hydrogen peroxide. ${ }^{7}$

An increased susceptibility to infection caused by the presence of NTBI would be at least partly masked by the risk of infection associated with neutropenia. During the period of observation in this study 26 pyrexial episodes were recorded, of which 16 were associated with a bacterial isolate. Due to the large overlap of the neutropenic period with the duration of detectable NTBI the relative contributions of either to the infections was difficult to analyse. With the advent of recombinant haemopoietic growth factors, however, such as granulocyte colony stimulating factor
(G-CSF), which can shorten periods of neutropenia, other potential risk factors for infection such as NTBI may become clinically significant.

We believe that further work in this area is justified to investigate the theory that NTBI contributes to the increased incidence of infection seen after cytotoxic chemotherapy.

1 Bately RG, Lai Chung Fong P, Shamir S, Sherlock S. A non transferrin bound serum iron in idiopathic haemachromatosis. Dig Dis Sci 1980;25:340-6.

2 Fargion S, Capellini MD, Sampietro M, Forelli G. Non specific iron in patients with beta thalassaemia trait and chronic active hepatitis. Scand $\mathcal{f}$ Haematol 1981;26: 161-7.

3 Caroline L, Rosner F, Kozinn PJ. Elevated serum iron, low unbound transferrin and candidiasis in acute leukaemia. Blood 1969;34:441-51.

4 Hunter RL, Bennett $B$, Towne $M$, Volger WR. Transferrin in disease II: defects in the regulation of Transferrin in disease II: defects in the regulation of
transferrin saturation contribute to susceptibility to transferrin saturation contribute to susce
infection. Am 7 Clin Pathol 1984;81:748-53.

5 Gutteridge JMC, Hou Y. Iron complexes and their reactivity in the bleomycin assay for radical promoting loosely bound iron. Free Radic Res Commun 1986;2:143-51.

6 Gutteridge JMC, Rowley DA, Halliwell B. Superoxide dependant formation of hydroxyl radicals in the presence of iron salts. Biochem $¥$ 1981;199:263-5.

7 Halliwell B, Aruoma OI, Mufti G, Bomford A. Bleomycindetectable iron in the serum from leukaemic patients before and after chemotherapy. FEBS Lett 1988;241: 202-4.

8 Potaznik N, Groshen S, Miller D, Bagin R, Bhalla R, Schwartz $M$, de Souza $M$. Association of serum iron, serum transferrin saturation, and serum ferritin with survival in acute lymphoblastic leukaemia. Am $\mathcal{f}$ Pediatr Hematol Oncol 1987;9:350-5.

9 Weinberg ED. Iron withholding: a defence against infection and neoplasia. Physiol Rev 1984;64:65-102.

10 Carbonetti NH, Boonchai S, Parry SH, Vaianen-Rhen V, Korhonen TK, Williams PH. Aerobactin-mediated iron uptake by Escherichia coli isolates from human extraintestinal infections. Infect Immun 1986;51:966-968.

11 Oppenheimer SJ, Iron and infection: the clinical evidence. Acta Paediatr Suppl 1989;361:53-62.

12 Brock JH. Iron and infection. Haematologia 1987;20: $237-46$.

13 Brock JH. The effects of iron and transferrin on the response in serum-free cultures of mouse lymphocytes to concanavalin a and lipopolysaccharide. Immunology 1981;43:387-95.

14 Van Asbeck BS, Marx JJM, Struyvenberg A, Van Kats JH, Verhoef J. Effect of iron (III) in the presence of various ligands on the phagocytic and metabolic activity of human polymorphonuclear leukocytes. F Immunol 1984; 132:851-6. 